\title{
Nutritional status of diabetic patients attending Sir Sunderlal Hospital, B.H.U.Varanasi (2000-2014): An interventional study
}

\author{
SUKANYA CHAKRAVORTY, N.K. AGRAWAL AND ARCHANA CHAKRAVARTY
}

See end of the paper for authors' affiliation Correspondence to : SUKANYA CHAKRAVORTY Department of Home Science (Food and Nutrition) Mahila Maha Vidhyalaya, Banaras Hindu University, VARANASI (U.P.) INDIA

Email: su.chakravorty@ gmail.com

KEY WORDS :

Diabetes, Nutritional Status, BMI, Diet, Drug
ABSTRACT : Diabetic patients encounter several difficulties in complying with the dietary regime. They express feelings of dietary deprivation and rigid dietary control is perceived as the only way to a proper diet and weight management. The main aim of the study is to know the impact of counseling on anthropometry, biochemical values and dietary intake of diabetic patients. The present paper is a compilation of studies carried out on diabetic patients from year 2000 to 2014. The result shows the prevalence rate, BMI, nutrient consumption pattern and blood values (Fasting and post prandial sugar level) of pre and posts diet counseling. The main objectives of the studies carried out in different years were to assess the impact of diet counseling on the blood values and BMI of the studied diabetic patients.All the studies were carried out on patients attending OPD of Endocrinology Department Sir Sunderlal Hospital Varanasi. Samples were selected purposively. The pre- tested questionnaires were used to assess their nutritional status. The 24 hour diet recall method was used to assess their dietary intake. Patients of all the year were based on diet and drug. Based on the studies of all the survey it can be concluded that from year 2000 to 2014 there has been a significant change in the food intake of diabetic patients. According to their weight a difference in BMI was observed. Blood value of patients has also changed due to effect of diet and BMI.

How to cite this paper : Chakravorty, Sukanya, Agrawal, N.K. and Chakravarty, Archana (2015).Nutritional status of diabetic patients attending Sir Sunderlal Hospital, B.H.U.Varanasi (2000-2014): An interventional study. Internat. J. Med. Sci., 8(1\&2) : 5-9. 